Gut, 1989, 30, 1385-1391

\title{
Significance of venous and lymphatic invasion in malignant polyps of the colon and rectum
}

\author{
S MULLER, I M CHESNER, M J EGAN, D C ROWLANDS, M J COLLARD, \\ E T SWARBRICK, AND J NEWMAN
}

From the Departments of Gastroenterology and Pathology, East Birmingham Hospital, and Selly Oak Hospital, Birmingham, and New Cross Hospital, Wolverhampton

SUMmARY Three hundred and sixty seven neoplastic colorectal polyps removed at endoscopy of which 34 were complicated by invasive carcinoma, were reviewed clinically and histologically to assess the prevalence and clinical significance of venous and or lymphatic invasion. Traditional stains for histological assessment were supplemented by immunohistochemical methods. Venous

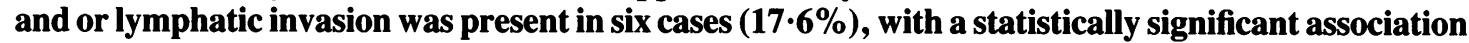
with recurrent carcinoma or Dukes's C carcinoma in polyps otherwise regarded as completely excised. The presence or absence of venous and or lymphatic invasion in malignant polyps should be documented as if present, further treatment is indicated. A combination of haematoxylin and eosin and elastic-van Gieson stains will usually identify the presence of vascular invasion. Where a discrepancy arises, however, additional immunohistochemical stains may be of value.

Endoscopic removal of colorectal polyps has now become a routine procedure. On histologic examination some neoplastic polyps are found to contain invasive carcinoma and, despite a considerable volume of literature, their optimal management is still controversial. While many believe endoscopic polypectomy alone to be sufficient, provided certain histologic criteria are met, ${ }^{1-5}$ others advocate radical surgery in order to eradicate potentially curable local disease. ${ }^{n-4}$

One factor that has been suggested as indicating a poor prognosis is the presence of venous and or lymphatic invasion. ${ }^{24910}$ Although this is an infrequent finding ${ }^{5}$ its presence has been claimed to have a high predictive value for an adverse outcome."112 With this in mind we reviewed 367 endoscopically removed neoplastic colorectal polyps greater than $1 \mathrm{~cm}$ diameter. Thirty four contained invasive carcinoma and these were subjected to a variety of empirical and immunohistochemical stains in order to identify venous and or lymphatic invasion by

Address for correspondence: Dr J Newman, Department of Histopathology, East Birmingham Hospital, Bordesley Green East, Birmingham B9 5ST.

Accepted for publication 9 February 1989. tumour. These findings were then analysed in relation to operative and eventual outcome.

\section{Methods}

All endoscopically removed neoplastic colorectal polyps greater than $1 \mathrm{~cm}$ diameter were retrieved from three hospitals in the West Midlands for the five year period 1981 to 1985 . A total of 367 neoplastic polyps were examined. All slides and reports were reviewed by two pathologists (SM and JN). The majority of polyps, 297, were completely removed small adenomas showing only mild or moderate dysplasia. A further 36 showed severe dysplasia, and the remaining 34 showed invasive carcinoma.

The 34 polyps with invasive carcinoma were subjected to further study. Excluded from this study were polyps arising in patients with a known colorectal carcinoma (past or synchronous), familial adenomatous polyposis, and cases without full follow up details.

The adenomatous element was classified as either tubular, tubulovillous, or villous according to standard histopathologic criteria. Other factors noted were the degree of epithelial dysplasia, the degree of differentiation of the carcinoma (well, moderately, 
or poorly differentiated), the depth of invasion of the carcinoma $(\mathrm{mm})$ and the presence of venous and or lymphatic invasion. Polypoid adenocarcinomas without evidence of pre-existing adenoma were excluded; as were frankly invasive sessile adenocarcinomas.

Completeness of excision was assessed from the endoscopist's operative notes in conjunction with the microscopic appearance. Histologic incompleteness of excision was defined according to the criteria laid down by Morson. ${ }^{.}$Clinical details (age, sex, site, size of polyp), the surgical procedure(s) undertaken, and the eventual outcome were extracted from the case notes.

Subsequent clinical management depended upon the endoscopists' view as to completeness of removal, the histological appearances on sectioning, and the individual clinician's viewpoint. All patients have had at least one follow up colonoscopy and most are under regular colonoscopic review. The minimum period of follow up is 12 months and the maximum is five years.

If further surgery was indicated it was done within 10 days. The resected specimens were carefully inspected for any evidence of residual tumour at the site of polypectomy (although in some cases the site could not be clearly identified), and for lymph node status.

All polyps were fixed in $10 \%$ formol saline. Macroscopic examination included a careful search for a stalk, and marking its base with Indian ink. The material was then embedded in standard Tissue-Tek moulds with the stalk in the horizontal plane and excess tissue trimmed off each side of the head and separately embedded. Sections were cut at $5 \mu \mathrm{m}$ and in most cases multiple levels were cut in order to reach the middle of the stalk. Sections were stained with haematoxylin and eosin ( $\mathrm{H} \& \mathrm{E})$; and in order to look for vascular invasion the following stains were also used - elastic-van Gieson (EVG) to show collagen, muscle and elastic fibres,,$^{13}$ and picroMallory's stain (PM) to show fibrin, muscle and collagen, ${ }^{14}$ and immunohistochemical methods for Factor VIII related antigen (FVIII RAG) (Dako Ltd, High Wycombe, Bucks) collagen 4 protein (C4) (Bio-Nuclear Services Ltd, Reading) and Ulex Europaeus agglutinin type 1 (UEA-1) (Dako Ltd).

The immunohistochemical procedures were performed with the usual controls and conditions. Details of the methods, reagents and features demonstrated are given in Table 1. For assessment and interpretation of vascular invasion the slides were examined by both pathologists without prior knowledge of eventual outcome. In four cases where there was observer variation the slides were scrutinised and discussed by both pathologists using a discussion microscope.

Results were analysed statistically using Fisher's exact test. A positive outcome was defined as recurrent carcinoma at follow up (12-60 months) or Dukes's C (nodal) disease at operation. A negative outcome was recorded when the patient was alive and well at follow up, died of unrelated disease, was free of disease at operation, or was found to have only residual local disease after the initial incomplete endoscopic removal.

\section{Results}

Three hundred and sixty seven endoscopically removed colorectal polyps were examined; 34 of these were complicated by invasive carcinoma $(9 \cdot 2 \%)$.

The course of the 34 polyps with carcinoma (one in each patient) is summarised in Table 2. Fifteen, judged to have had either a doubtful or incomplete excision, went to surgery. Residual tumour was found in eight patients: six Dukes's A, one Dukes's B signet-ring carcinoma, one Dukes's $\mathrm{C}$ with serosal

Table 1 Details of immunohistochemistry

\begin{tabular}{|c|c|c|c|}
\hline Antibody & $F V I I I R A G$ & C4 & $U E A-I$ \\
\hline $\begin{array}{l}\text { Type } \\
\text { Pre-treatment } \\
\text { Endogenous }\end{array}$ & $\begin{array}{l}\text { Polyclonal } \\
0 \cdot 1 \% \text { Trypsin in TRIS } 20 \mathrm{~min}\end{array}$ & $\begin{array}{l}\text { Polyclonal } \\
0.5 \% \text { pepsin in } 0.01 \mathrm{~mol} \\
\mathrm{HC1} 120 \mathrm{~min}\end{array}$ & $\begin{array}{l}\text { Polyclonal } \\
0 \cdot 1 \% \text { Trypsin in TRIS } \\
20 \mathrm{~min} \\
\text { Nil }\end{array}$ \\
\hline $\begin{array}{l}\text { peroxidase } \\
\text { blocked } \\
\text { Dilution of } 1^{\circ} \text { antiserum }\end{array}$ & $\mathbf{M}$ & $1015 \mathrm{~min}$ & \\
\hline $\begin{array}{l}\text { Type and } \\
\text { dilution of } \\
2^{\circ} \text { antiserum }\end{array}$ & $-\mathrm{S}$ & anti-rabbit & $\begin{array}{l}\text { Peroxidase conjugated } \\
\rightarrow \text { rabbit immunoglobulins } \\
\text { to UEA-1 }\end{array}$ \\
\hline $\begin{array}{l}\text { Procedure } \\
\text { Feature demonstrated }\end{array}$ & $\begin{array}{l}\text { Peroxidase-antiperoxidase } \\
\text { Endothelial cells of veins }\end{array}$ & $\begin{array}{l}\text { Peroxidase-antiperoxidase } \\
\text { Basement membrane }\end{array}$ & $\begin{array}{l}\text { Indirect peroxidase } \\
\text { Endothelial cells of veins } \\
\text { and lymphatics }\end{array}$ \\
\hline
\end{tabular}


Table 2 Details of 34 cases of invasive carcinoma. Follow up period one to five years

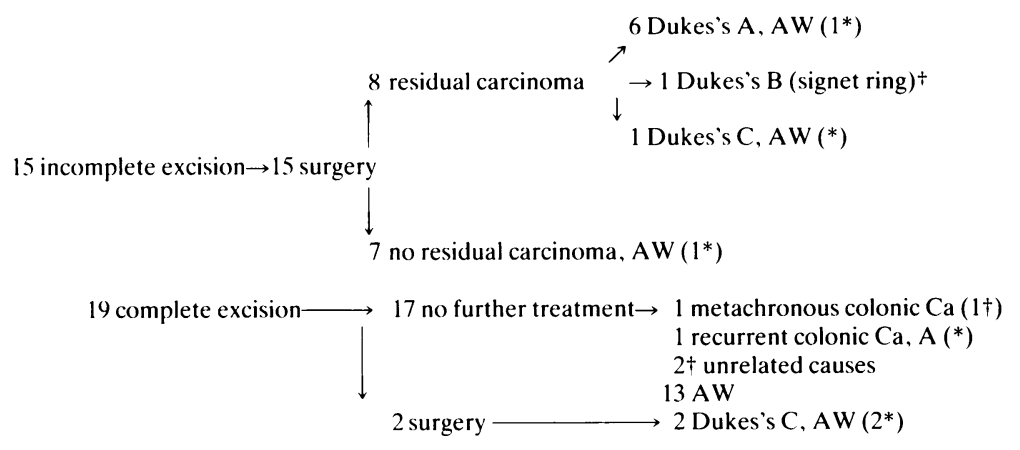

*vascular invasion identified, † died; AW Alive, well

involvement and metastasis in one of three lymph nodes. The Dukes's A and $\mathrm{C}$ patients are alive and well at 24-62 months; the Dukes's B case died of carcinoma at 10 months. Seven had no residual tumour and all these are well at 12-56 months.

Nineteen patients were judged to have had a complete excision on conventional criteria. Seventeen had no further treatment; two dying of unrelated causes (without evidence of colonic neoplasm) while another two developed colorectal carcinoma at 14 and 16 months, the latter patient has since died of disseminated carcinoma secondary to a second colonic primary at a site distant to the previous polypectomy. The former developed the recurrence at the site of previous polypectomy and was again locally treated. In the interim carcinoma of the stomach was diagnosed and treated conservatively. Two further patients had colonic resections because of the presence of venous and or lymphatic invasion and both specimens contained Dukes $\mathrm{C}$ carcinoma. There was no residual local tumour but metastatic carcinoma was found in one of eight and one of four local lymph nodes. These two patients are alive at 10 and 24 months.

The histological parameters and outcome of the carcinomas are summarised in Table 3 . Venous and

Table 3 Histological features and outcome of invasive carcinoma

\begin{tabular}{|c|c|c|c|c|c|c|c|}
\hline Variable & Parameter & $N$ & $\%$ & Dukes's $A / B$ & Dukes's $C$ & $\begin{array}{l}\text { NEOM at } \\
\text { operation }\end{array}$ & $\begin{array}{l}\text { No } \\
\text { operation } \\
\text { (recurrent } \\
\text { tumour) }\end{array}$ \\
\hline \multirow[t]{3}{*}{1 Size } & $<20 \mathrm{~mm}$ & 16 & $47 \cdot 0$ & 2 & 1 & 5 & $8(1)$ \\
\hline & $20-29 \mathrm{~mm}$ & 9 & $26 \cdot 5$ & 2 & 1 & 1 & 5 \\
\hline & $>30 \mathrm{~mm}$ & 9 & $26 \cdot 5$ & 3 & 1 & 1 & $4(1)$ \\
\hline \multirow[t]{3}{*}{2 Depth of invasion } & $0-4 \mathrm{~mm}$ & 22 & $64 \cdot 7$ & 4 & 1 & 4 & $13(1)$ \\
\hline & $5-9 \mathrm{~mm}$ & 7 & $20 \cdot 6$ & 2 & - & 3 & $2(1)$ \\
\hline & $>10 \mathrm{~mm}$ & 5 & $14 \cdot 7$ & 1 & 2 & - & 2 \\
\hline \multirow{7}{*}{$\begin{array}{l}\text { Degree of } \\
\text { differentiation }\end{array}$} & Well & 4 & $11 \cdot 8$ & - & - & 1 & 3 \\
\hline & Moderate & 29 & $85 \cdot 3$ & 6 & 3 & 6 & $14(2)$ \\
\hline & Poor & 1 & $2 \cdot 9$ & 1 & - & - & - \\
\hline & $\begin{array}{l}\text { Complete excision and } \\
\text { vascular invasion }\end{array}$ & 3 & $8 \cdot 8$ & - & 2 & - & $1(1)$ \\
\hline & $\begin{array}{l}\text { Incomplete excision and } \\
\text { vascular invasion }\end{array}$ & 3 & $8 \cdot 8$ & 1 & 1 & 1 & - \\
\hline & $\begin{array}{c}\text { Complete excision and } \\
\text { no vascular invasion }\end{array}$ & 16 & $47 \cdot 0$ & - & - & - & $16(1)$ \\
\hline & $\begin{array}{l}\text { Incomplete excision and no } \\
\text { vascular invasion }\end{array}$ & 12 & $35 \cdot 2$ & 6 & - & 6 & 0 \\
\hline
\end{tabular}

NEOM No evidence of malignancy 
Table 4 Details of special stains in individual cases with positive vascular invasion

\begin{tabular}{|c|c|c|c|c|c|c|c|c|c|}
\hline Case no & $H \& E$ & $P M$ & $E V G$ & $U E A$ & $F V I I I$ & $C 4$ & $\begin{array}{l}\text { Vessel } \\
\text { invaded }\end{array}$ & $\begin{array}{l}\text { Completeness } \\
\text { of excision }\end{array}$ & Outcome \\
\hline 1 & + & + & + & + & + & - & $V$ and $v$ & - & AR NEOM \\
\hline 2 & + & + & - & - & - & - & V & - & SC Dukes'C \\
\hline 3 & - & - & + & + & + & + & $V$ and $v$ & - & APR Dukes`A \\
\hline 4 & + & + & - & + & + & + & $v$ & + & Recurrent cancer \\
\hline 5 & + & - & + & - & - & - & V & + & SC Dukes`C \\
\hline 6 & + & + & + & - & - & - & $\mathrm{V}$ and $\mathrm{L}$ & + & AR Dukes`C \\
\hline
\end{tabular}

$\mathrm{V}$ - venous invasion; $\mathrm{L}$ - lymphatic invasion; $\mathrm{v}$ - vascular invasion; $\mathrm{AR}$ - anterior resection: $\mathrm{APR}$ - abdomino-perineal resection: $\mathrm{SC}$ - segmental colectomy.

or lymphatic invasion was seen in six cases $(17 \cdot 6 \%)$ being present within the submucosal vessels contained within the stalk. In three cases this was present in polyps where the malignanacy was regarded as having been incompletely excised and in three as completely excised as judged by conventional criteria. The fine vasculature within the lamina propria was far more difficult to discern, being delineated primarily with the immunostains. There was no identifiable tumour invasion within these vessels. On the $\mathrm{H} \& \mathrm{E}$ five cases were positive and this finding was confirmed by at least one positive special stain (Figs. 1,2). One further case had four positive special stains but absence of clear invasion on $\mathrm{H} \& \mathrm{E}$; this was regarded as positive for venous and or lymphatic invasion. In two cases, however, isolated positive special stains were seen and these were regarded as false positives. A summary of the results of the special stains is found in Table 4.

In general the EVG was the easiest stain to interpret, as it highlighted the elastica of larger vessels, but this only confirmed three cases and helped identify one further case. Although veins and arteries were delineated from the surrounding stroma, stromal fibrosis did pose a problem with regard to smaller vessels possessing little or no elastica (Fig. 3). The latter was also a problem with the PM stain, and here vessel walls were even less well delineated. No fibrin thrombi were seen in any of the cases with obvious vascular invasion.

The immunostains were disappointing. They were more difficult to interpret and only confirmed three cases. They outlined small submucosal vessels in addition to the larger veins and arteries highlighted by the EVG. The FVIII RAG did not stain as many vessels as C4 or UEA-1. In many places fragmentation of vessel walls and fibrosis/destruction resulted in very patchy staining.

The UEA-1 consistently showed mural and mucosal vasculature with very little background staining (Fig. 4). The main drawback was its lack of specificity, with concurrent positive staining in red cells, muciphages, and some of the dysplastic and malignant epithelial cells. The $\mathrm{C} 4$ showed basement membranes in vessels of the lamina propria and submucosa, with little background staining. Its usefulness was limited by the fact that gland basement membrane was also outlined.

In four cases there was obvious venous involvement, the EVG confirming the nature of the structure invaded. In one case definite lymphatic invasion was also present. In two cases in addition to obvious venous invasion there was also smaller vascular channel invasion in which the nature of the vascular channel could not be identified with certainty. In two further cases only small vascular channels were invaded.

Five of the six cases with vascular invasion had further surgery. Four had positive findings - that is, three Dukes's C, one Dukes's A (Table 3). The one case that did not have further surgery developed recurrent colon carcinoma at the site of the previous polypectomy, hence five of the six had adverse results $(83 \%)$. Two of the five would have been recommended for further treatment as excision was thought to be incomplete. The three with moderately differentiated carcinoma clear of the excision plane on initial polypectomy would not, however, have had a further operation.

Statistical analysis using Fisher's exact test showed that vascular invasion was an adverse prognostic factor both for completely removed $(p=0 \cdot 0041)$ and for all malignant polyps whether or not completely removed $(p=0.0044)$. Other factors - that is, type of polyp, degree of differentiation, site (colonic $v$ rectal), depth of invasion, and size did not correlate with outcome.

\section{Discussion}

There have been several studies reviewing the pathology, management, and outcome of endoscopically resected malignant colorectal polyps ${ }^{1-12}$ and the criteria upon which complete resection can 


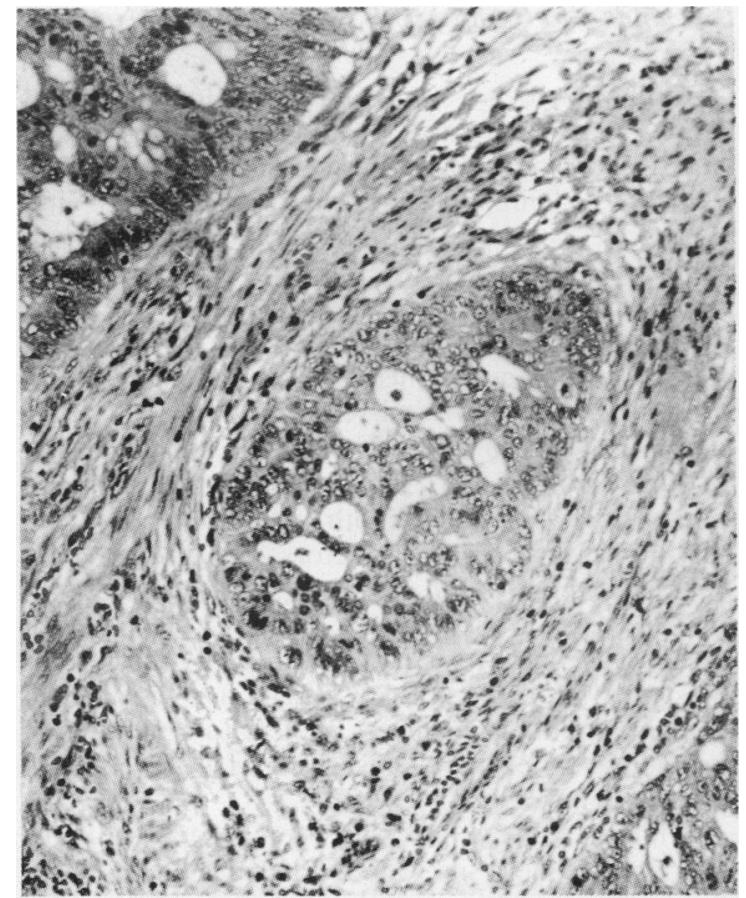

Fig. 1

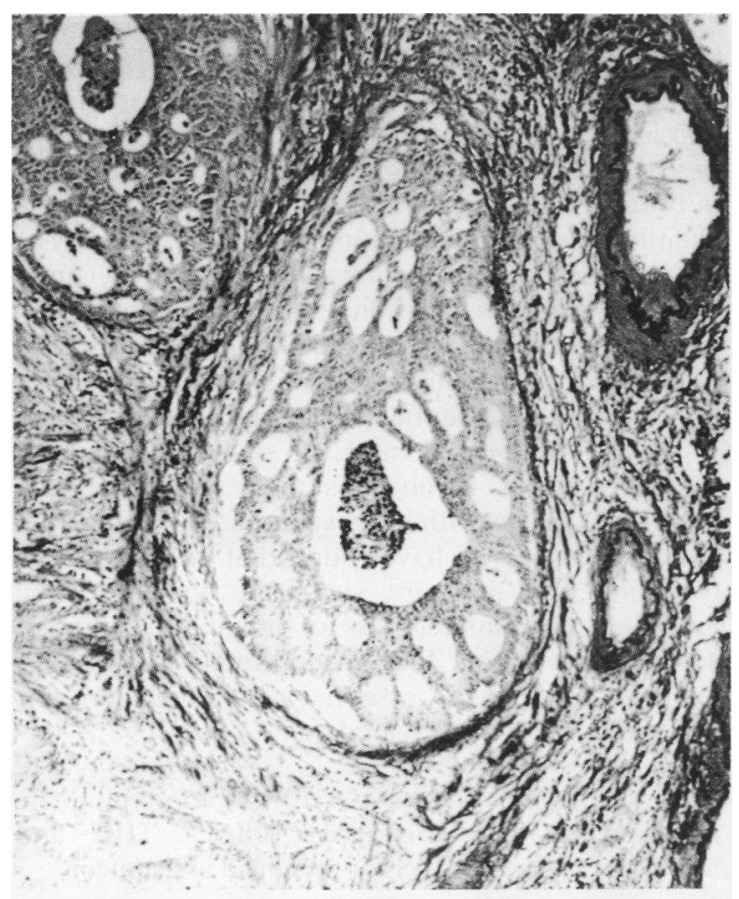

Fig. 3

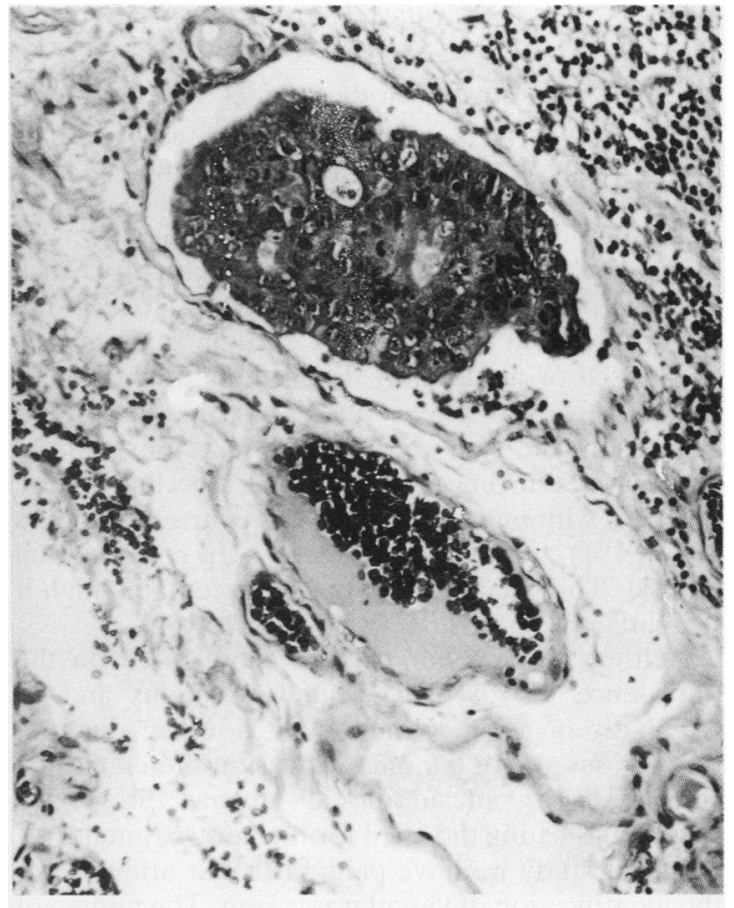

Fig. 2

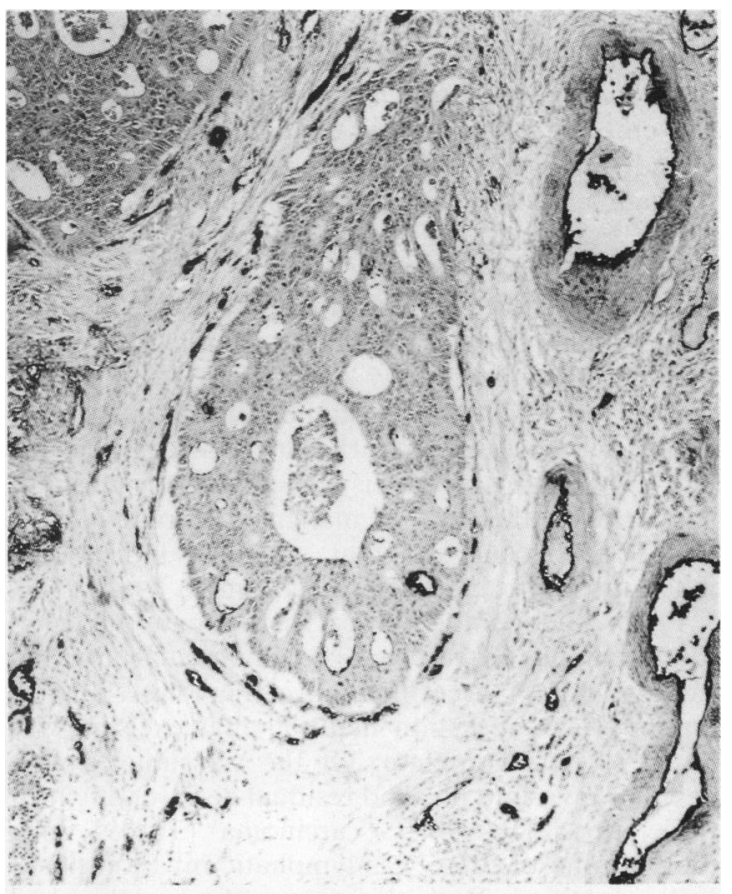

Fig. 4

Fig. 1 Small submucosal vascular channel within the main body of a polyp. $H \& E$.

Fig. 2 Small lymphatic channel within the deep portion of the stalk of a polyp distended by a denocarcinoma. $H \& E$.

Fig. 3 Tumour distending a small vein within the submucosa of the main body of a polyp. EVG.

Fig. 4 Same vein as in Figure 3 showing intravascular tumour. UEA-1. 
be ascertained have been the subject of debate. The reported series have stressed the need for meticulous preparation, orientation, and sectioning of the material, ${ }^{15}$ and the heavy dependence on the accuracy of histological reporting. There were no recurrences in Morson's prospective study of 46 patients over a five year period treated by polypectomy alone, using the criteria of a resection line clear of tumour cells and a well or moderately differentiated carcinoma. Others, however, ' have reported a recurrence rate of $21 \%$ using the same criteria for resection; similar figures for recurrence are given by Colacchio." These compare with our findings of four recurrent tumours in $19(21 \%)$ considered fully resected by conventional criteria. This recurrence rate is unacceptably high if the patient is fit for surgery.

Neither Morson nor Cooper commented on the prevalence of vascular - that is, venous and or lymphatic invasion. Others, ${ }^{23+411}$ however, suggest that venous and or lymphatic invasion should also be considered as an additional adverse prognostic feature indicating the need for further treatment.

In this study we have paid particular attention to the identification of vascular invasion. The finding of six of $34(17.6 \%)$ is higher than that found in other series $^{5 t}$ and may reflect a more extensive and careful search. We would agree with Morson that meticulous histological preparation is of the utmost importance, and emphasise the need to examine multiple levels. Blundell ${ }^{15}$ described one case where multiple sections through a block revealed vascular invasion not seen on the original levels, and as a result of this further surgery was carried out. Talbot ${ }^{16}$ noted vascular invasion in $20 \%$ of (surgically removed) Dukes's A rectal carcinomas, claiming that simple laboratory methods provided ready and easy detection. He noted, however, that this did not alter the prognosis of Dukes's A lesions, in stark contrast with Dukes's B and $\mathrm{C}$ where the prognosis worsened. This does not appear to be the case for malignant colonic polyps, and Riddell" suggests that this may indicate an inherently more aggressive neoplasm.

In our study, of the four polyps 'wrongly' allocated to the completely resected group, vascular invasion was apparent in three. Therefore, there was evidence on the initial resection material that excision was likely to be incomplete. Of the six subjects with vascular invasion, five had residual disease, of which three were Dukes's C carcinoma (Tables 2,4). Only in one of these was lymphatic invasion positively identified. Both this case and one other had additionally overt venous invasion. The remaining Dukes's C carcinoma showed only small vessel invasion. Although in four cases venous invasion was demonstrated none have developed blood borne metastases. This suggests that vascular invasion, if present, is associated with a poor outlook - a point emphasised by Stamm. ${ }^{17}$ He reviews 10 cases of invasive carcinoma occurring at the tip of polyps with evidence of lymphatic invasion away from that site. Only four of his polyps were poorly differentiated. Similarly, in our study, de-differentiation was not a feature of those polyps associated with vascular invasion. Only one of our polyps had poorly differentiated carcinoma and this was incompletely excised and associated with local recurrence. Unlike other observers we did not find that site of the lesion (colonic $v$ rectal), ${ }^{3}$ the external appearance (sessile $v$ pendunculated),,$^{2+}$ the depth of invasion, ${ }^{3}$ or the tumour size accurate predictors of outcome, only venous and or lymphatic invasion correlated with outcome.

Recognition of vascular invasion $1{ }^{111}$ by the pathologists, while requiring meticulous histological examination is nevertheless subject to a number of problems - for example, observer variation, sampling error, artefact, etc.

While in the past EVG has been used as a marker for large vessels, its value in identifying tumour invasion is limited especialy with regard to smaller vessels.

Although there are several immunohistochemical markers available for looking at veins and lymphatics with conflicting results, ${ }^{20-2 \mathrm{Z}}$ the combination of $\mathrm{H} \& \mathrm{E}$ and EVG stains will usually indicate the presence of vascular invasion. Where there is a discrepancy between these two stains additional immunohistochemical stains may be helpful in deciding one way or the other. Similar findings have been recently reported in an investigation of breast carcinoma."

Care in the trimming and embedding of all resected polyps with meticulous examination of the sections at multiple levels is essential. Where invasive carcinoma is present both $\mathrm{H} \& \mathrm{E}$ and $\mathrm{EVG}$ stains are required. The extra work involved is not excessive as the number of polyps with invasive disease is small.

In conclusion we have found that venous and or lymphatic invasion are significant criteria when assessing the completeness of polyp excision. An active search for these additional features in malignant polyps is essential and when present colonic resection is indicated.

We are grateful to Mrs V Griffiths for typing the manuscript and Christopher Davies TEC and Michael J Chard FIMLS for technical assistance.

\section{References}

1 Morson BC. Whiteway JE. Jones EA. Macrac FE, Williams CB. Histopathology and prognosis of malignant colorectal polyps treated by endoscopic polypectomy. Gut 1984; 25: 437-44. 
2 Cooper HS. Surgical pathology of endoscopically removed malignant polyps of the colon and rectum. Am J Surg Pathol 1983; 7: 613-23.

3 Haggitt RC, Glotzbach RE, Soffer EE, Wruble LD. Prognostic factors in colorectal carcinomas arising in adenomas: implications for lesions removed by endoscopic polypcctomy. Gastroenterology 1985; 89: 328-36.

4 Christic JP. Malignant colon polyps - cure by colonoscopy or colectomy? Am J Gastroenterol 1974; 79: 543-7.

5 Cranley JP, Petras RE, Carey WD, Paradis K, Sivak $\mathrm{MV}$. When is endoscopic polypectomy adequate therapy for colonic polyps containing invasive carcinoma? Gastroenterology 1986; 91: 419-27.

6 Colacchio TA, Forde KA, Scantlebury VP. Endoscopic polypectomy - inadequate treatment for invasive colorectal carcinoma. Ann Surg 1981; 194: 704-7.

7 Wilcox GM, Colacchio TA. Reply to selected summary: is polypectomy alone adequate for carcinoma in situ? Gastroenterology 1982; 83: 716-7.

8 Wayc JD. An approach to malignant polyps. Gastrointest Endosc 1984; 30: 310-11.

9 Wolff WI, Shinya $H$. Definitive treatment of "malignant" polyps of the colon. Ann Surg 1975; 182: 516-25.

10 Wilcox GM, Anderson P, Colacchio TA. Early invasive cancer in colonic polyps - a review of the literature with emphasis on the assessment of the risk of metastasis. Cancer 1986; 57: 160-71.

11 Riddell RH. Hands off "cancerous" large bowel polyps. [Editorial] Gastroenterology 1985; 89: 432-5.

12 Shatney CH, Lober PH, Gilbertsen VA, Sosin H. The treatment of pendunculated adenomatous colorectal polyps with focal cancer. Surg Gynecol Obstet 1974; 139: $84.5-50$.

13 Miller PJ. An elastin stain. Med Lab Tech 1971; 28: 148-9.

14 McFarlane D. Picro-Mallory; easily controlled regressive trichromic staining method. Stain Technol 1944; 19: 29-37.

15 Blundell CR, Earnest DL. A caution concerning conservative management of colonic polyps containing invasive carcinoma. Gastrointest Endosc 1980; 26: 54-5.

16 Talbot IC. Spread of rectal cancer within veins and mechanisms of malignant cmbolism. In: Wright $\mathrm{R}$, ed. Recent advances in gastrointestinal pathology. Philadelphia: WB Saunders, 1980: 353-64.

17 Stamm B. Ristivojevic B. Small pedunculated tubular adenoma of the colon with carcinoma restricted to the head, invasion of lymphatics, and widespread metastases. Virchows Archiv [Pathol Anat] 1983; 402: 83-9.

18 Fenoglio CM, Kaye GI, Lane N. Distribution of human colonic lymphatics in normal, hyperplastic, and adenomatous tissue - Its relationship to metastasis from small carcinomas in pedunculated adenomas, with 2 case reports. Gastroenterology 1973; 64: 51-6.

19 Fried GM, Hreno A, Duguid W, Hampson LG. Rational Management of Malignant colon polyps based on long-term follow up. Surgery 1984; 96: 815-21.

20 Bettelheim R, Mitchell D, Gusterson BA. Immunocytochemistry in the identification of vascular invasion in breast cancer. J Clin Pathol 1984; 37: 364-6.

21 Lee AKC, De Lellis RA, Silverman ML, Wolfe HJ. Lymphatic and blood vessel invasion in breast carcinoma - a useful prognostic indicator? Hum Pathol 1986; 17: 984-7.

22 Little D, Said JW, Siegel RJ, Fealy M, Fishbein MC. Endothelial cell markers in vascular neoplasms; an immunohistochemical study comparing Factor VIIIrelated antigen, blood group specific antigens, 6 ketoPGF1 alpha, and Ulex Europaeus 1 Lectin. J Pathol 1986; 149: 89-95.

23 Harach HR, Jasani B, Williams ED. Factor VIII as a marker of endothelial cells in follicular carcinoma of the Thyroid. J Clin Pathol 1983; 36: 1050-4.

24 Leader M, Collins M, Patel J, Henry K. Staining for Factor VIII related antigen and Ulex Europaeus agglutinin I (UEA-I) in 230 tumours. An assessment of their specificity for angiosarcoma and Kaposi's sarcoma. Histopathology 1985; 10: 1153-62.

25 Holthöfer H, Virtanen I, Kariniemi A-L, Hormia M, Linder E, Miettinen A. Ulex Europaeus I lectin as a marker for vascular endothelium in human tissues. $L a b$ Invest 1982; 47: 60-6.

26 Rhodes JM, Black RR, Savage A. Glycoprotein abnormalities in colonic carcinomata, adenomata, and hyperplastic polyps shown by lectin peroxidase histochemistry. J Clin Pathol 1986; 39: 1331-4.

27 Burtin P. Chavanel G, Foidart JM, Martin E. Antigens of the basement membrane and the peritumoral stroma in human colonic adenocarcinomas; an immunofluorescence study. Int J Cancer 1982; 30: 13-20.

28 Kendall CH, Sanderson PR, Cope J, Talbot IC. Follicular thyroid tumours: a study of laminin and type IV collagen in basement membrane and endothelium. J Clin Pathol 1985; 38: 1100-5.

29 Saigo PE, Rosen PP. The application of immunohistochemical stains to identify endothelial-lined channels in mammary carcinoma. Cancer 1987; 59: 51-4. 